\title{
Solid-Liquid Equilibria for 3-Aminophenol + 2-Aminophenol, 4-(Acetylamino)toluene + 2-(Acetylamino)toluene, and 3,4,5-Trimethoxybenzoic Acid + 2,4,5-Trimethoxybenzoic Acid
}

\author{
Chih-Yung Huang, ${ }^{\dagger}$ Muoi Tang, ${ }^{\dagger}$ and Yan-Ping Chen*,*
}

Department of Chemical Engineering, Chinese Culture University, and Department of Chemical Engineering, National Taiwan University, Taipei, Taiwan, ROC

\begin{abstract}
Solid-liquid equilibria for three isomeric binary mixtures of 3 -aminophenol (1) +2 -aminophenol (2) (eutectic temperature $T_{\mathrm{E}}=376.5 \mathrm{~K}$, eutectic composition $\left.x_{1 \mathrm{E}}=0.86\right)$, 4-(acetylamino)toluene (1) + 2-(acetylamino)toluene $(2)\left(T_{\mathrm{E}}=357.2 \mathrm{~K}, x_{1 \mathrm{E}}=0.30\right)$, and 3,4,5-trimethoxybenzoic acid $(1)+2,4,5$ trimethoxybenzoic acid $(2)\left(T_{\mathrm{E}}=395.8 \mathrm{~K}, x_{1 \mathrm{E}}=0.33\right)$ were measured using differential scanning calorimetry (DSC). Simple eutectic behaviors for these systems were observed. The experimental results were correlated using the Wilson activity coefficient model. The eutectic compositions were also determined using Gray's model and the fractional transformation method.
\end{abstract}

\section{Introduction}

On purifying the isomeric compounds where traditional methods are inapplicable, solid-liquid separation may suggest a feasible solution. Solid-liquid equilibrium (SLE) data are thus important to such process design. SLE is conventionally determined by a cooling curve or visual measurement. ${ }^{1}$ An alternative approach is the application of differential scanning calorimetry (DSC) where many systems of metal, polymer, and organic compounds were reported. ${ }^{2,3}$ The DSC method measures the heat effect during the phase transformation, and the phase boundaries are evaluated. ${ }^{4}$ Several mathematical models for DSC were presented in the literature..$^{3,5}$ Using these models and the experimentally measured SLE data, the eutectic-point temperature and composition are more accurately determined than those from traditional methods.

In this study, SLE data for three isomeric organic systems of 3 -aminophenol $\left(\mathrm{C}_{6} \mathrm{H}_{7} \mathrm{NO}\right)+2$-aminophenol, 4 -(acetylamino)toluene $\left(\mathrm{C}_{9} \mathrm{H}_{11} \mathrm{NO}\right)+2$-(acetylamino)toluene, and 3,4,5-trimethoxybenzoic acid $\left(\mathrm{C}_{10} \mathrm{H}_{12} \mathrm{O}_{5}\right)+2,4,5$ trimethoxybenzoic acid were measured using DSC. The eutectic points for these systems were determined by employing the fractional transformation model. The experimental data were also correlated by applying the thermodynamic activity coefficient model.

\section{Experimental Section}

2-Aminophenol and 3-aminophenol were purchased from Merck, and the other chemicals were bought from Acros. The purity of each chemical was greater than $99 \%$, and they were used without further purification. Their melting temperatures and enthalpies of fusion were measured using DSC (DuPont TA2010). Table 1 lists the results and the comparison with available literature data. The measured melting temperatures for all pure compounds are in satisfactory agreement with literature data.

* Corresponding author. E-mail: ypchen@ntu.edu.tw. Fax: +886-22362-3040.

$\dagger$ Chinese Culture University.

* National Taiwan University.
Table 1. Comparison of the Measured Melting Temperatures with Literature Data for Pure Compounds

\begin{tabular}{lccc}
\hline & \multicolumn{2}{c}{$T_{\mathrm{m}} / \mathrm{K}$} & \\
\cline { 2 - 3 } \multicolumn{1}{c}{ compound } & exptl & lit $^{9}$ & \\
& 447.6 & 447.2 & 0.4 \\
2-aminophenol & 396.8 & 396.2 & 0.6 \\
3-aminophenol & 382.7 & 383.2 & 0.5 \\
2-(acetylamino)toluene & 424.0 & 425.2 & 1.2 \\
4-(acetylamino)toluene & 417.9 & 418.2 & 0.3 \\
2,4,5-trimethoxybenzoic acid & 444.5 & 445.5 & 1.0 \\
3,4,5-trimethoxybenzoic acid & 4 & & \\
${ }^{a} \Delta T=T_{\mathrm{m}}($ exptl $)-T_{\mathrm{m}}$ (lit). & & &
\end{tabular}

The SLE data were measured using the DSC equipment. For each binary system, the samples were prepared in a total amount of $10 \mathrm{~g}$ at a specific composition. The sample was ground to a uniform mixture, and $5 \mathrm{mg}$ of it was sealed in a high-pressure copper container made by DuPont Co. The accuracy of the balance (Precisa XB-120A) is $\pm 0.1 \mathrm{mg}$. The DSC was first purged with nitrogen gas and was heated to $773 \mathrm{~K}$ at a scanning rate of $10 \mathrm{~K} / \mathrm{min}$. The straight baseline was obtained at a scanning rate of 1 $\mathrm{K} / \mathrm{min}$ from room temperature to $523 \mathrm{~K}$ by adjusting the power output ratio of the microfurnaces. The DSC was calibrated using high-purity indium and zinc at a scanning rate of $1 \mathrm{~K} / \mathrm{min}$.

Each binary organic sample was initially melted by heating in the DSC to $473 \mathrm{~K}$, that is, over its melting temperature. It was then cooled to room temperature and maintained at this state for $30 \mathrm{~min}$. The DSC experiments were finally carried out at a heating rate of $1 \mathrm{~K} / \mathrm{min}$, and the measured curves were analyzed for SLE. The uncertainty in the temperature measurement is estimated to be $\pm 0.2 \mathrm{~K}$.

\section{Model and Correlation}

A heat-transfer model was proposed by $\mathrm{Gray}^{6}$ for the heat flow in DSC cells. Upon eliminating the baseline effect, Gray's model is written as ${ }^{3}$

$$
\frac{\mathrm{d} h(t)}{\mathrm{d} t}=-\frac{\mathrm{d} q(t)}{\mathrm{d} t} R C_{\mathrm{S}} \frac{\mathrm{d}^{2} q(t)}{\mathrm{d} t^{2}}
$$


Table 2. Measured Solid-Liquid Equilibrium Data for the 3-Aminophenol (1) + 2-Aminophenol (2) Binary System

\begin{tabular}{cccccl}
\hline$x_{1}$ & $T_{\mathrm{E}} / \mathrm{K}$ & $T_{\mathrm{L}} / \mathrm{K}$ & $f_{\mathrm{E}}$ & $\gamma_{1}$ & \multicolumn{1}{c}{$\gamma_{2}$} \\
\hline 0.000 & & 447.6 & 0.000 & 2.407 & 1 \\
0.050 & 376.8 & 442.1 & 0.029 & 2.191 & 1.003 \\
0.100 & 376.8 & 439.2 & 0.086 & 2.002 & 1.01 \\
0.150 & 376.5 & 435.8 & 0.152 & 1.843 & 1.023 \\
0.200 & 376.4 & 433.7 & & 1.706 & 1.041 \\
0.251 & 376.2 & 431.1 & 0.253 & 1.589 & 1.064 \\
0.301 & 376.5 & 428.2 & 0.336 & 1.491 & 1.091 \\
0.318 & 376.8 & 426.3 & 0.369 & 1.462 & 1.102 \\
0.401 & 377.0 & 422.9 & 0.410 & 1.335 & 1.163 \\
0.513 & 376.5 & 413.7 & 0.574 & 1.209 & 1.273 \\
0.550 & 377.0 & 407.1 & 0.652 & 1.177 & 1.32 \\
0.650 & 376.8 & 399.7 & 0.757 & 1.103 & 1.466 \\
0.701 & 377.2 & 396.0 & 0.802 & 1.074 & 1.556 \\
0.750 & 376.6 & 389.0 & 0.867 & 1.052 & 1.661 \\
0.899 & 376.7 & 384.2 & 0.825 & 1.008 & 2.041 \\
0.950 & 376.2 & 391.6 & 0.288 & 1.002 & 2.177 \\
1.000 & & 396.8 & 0.000 & 1 & 2.332
\end{tabular}

where $\mathrm{d} g / \mathrm{d} t$ is the enthalpy generation rate in the phase transformation, $\mathrm{d} q / \mathrm{d} t$ is the experimentally measured power difference (or heat flow) between the sample and reference cells, $R$ is the thermal resistance between the cells, and $C_{\mathrm{S}}$ is the specific heat of the sample.

At the end of the phase transformation, $\mathrm{d} q / \mathrm{d} t$ has its maximum value, and $\mathrm{d} h / \mathrm{d} t$ is zero. The DSC curve returns to its baseline according to an exponential curve

$$
\frac{\mathrm{d} q(t)}{\mathrm{d} t}=\left(\frac{\mathrm{d} q(t)}{\mathrm{d} t}\right)_{\max } \exp \left(-\frac{t}{R C_{\mathrm{S}}}\right)
$$

where $R C_{\mathrm{S}}$ is taken as a time constant in the DSC experiment and is evaluated from the measured results from the standards

To determine the eutectic temperatures and compositions accurately, we employed the fractional transformation method in this study. The fractional transformation is the fraction of a mixture that is liquefied. The mathematical expression for the fractional transformation $f_{\mathrm{L}}$ is

$$
f_{\mathrm{L}}(t)=\frac{\int_{0}^{t} \frac{\mathrm{d} h(t)}{\mathrm{d} t} \mathrm{~d} t}{\Delta H}
$$

The numerator is the enthalpy generated at time $t$, and the denominator is the total enthalpy of the phase transformation

$$
\Delta H=\int_{0}^{\infty}-\frac{\mathrm{d} h(t)}{\mathrm{d} t} \mathrm{~d} t
$$

Using the experimentally measured results, we determined the fractional transformation values at each time and the corresponding temperatures by using eqs 3 and 4 .

The thermodynamic relationship for SLE, ${ }^{7}$ neglecting the difference in heat capacities of the liquid and solid phases, gives

$$
\ln \left(\gamma_{i} x_{i}\right)=-\frac{\Delta H_{i}^{\mathrm{f}}}{R T_{\mathrm{m}, i}}\left(\frac{T_{\mathrm{m}, i}}{T}-1\right)
$$

where $T_{\mathrm{m}}$ is the melting temperature, $\Delta H^{\mathrm{f}}$ is the molar enthalpy of fusion, $\gamma$ is the activity coefficient, and $x$ is the equilibrium liquid composition. The activity coefficient $\gamma$ shown in eq 5 represents the nonideal solution behavior and is correlated by the Wilson ${ }^{8}$ model in this study. The Wilson model has two parameters (as listed in Table 5) for
Table 3. Measured Solid-Liquid Equilibrium Data for the 4-(Acetylamino)toluene $(1)+2$-(Acetylamino)toluene (2) Binary System

\begin{tabular}{cccccl}
\hline$x_{1}$ & $T_{\mathrm{E}} / \mathrm{K}$ & $T_{\mathrm{L}} / \mathrm{K}$ & $f_{\mathrm{E}}$ & $\gamma_{1}$ & \multicolumn{1}{c}{$\gamma_{2}$} \\
\hline 0.000 & & 382.7 & 0.000 & 0.396 & 1 \\
0.050 & 357.7 & 378.5 & 0.161 & 0.449 & 0.996 \\
0.101 & 356.9 & 375.2 & & 0.505 & 0.986 \\
0.151 & 357.6 & 370.5 & 0.496 & 0.557 & 0.971 \\
0.200 & 357.4 & 367.6 & 0.667 & 0.608 & 0.951 \\
0.399 & 357.1 & 372.9 & 0.852 & 0.796 & 0.854 \\
0.450 & 357.0 & 380.3 & 0.780 & 0.836 & 0.83 \\
0.499 & 357.2 & 384.8 & 0.708 & 0.869 & 0.806 \\
0.547 & 357.5 & 388.8 & 0.660 & 0.896 & 0.782 \\
0.600 & 357.2 & 394.6 & 0.556 & 0.922 & 0.758 \\
0.650 & 357.1 & 397.3 & 0.512 & 0.942 & 0.733 \\
0.699 & 357.0 & 401.3 & 0.411 & 0.959 & 0.711 \\
0.799 & 357.1 & 409.1 & 0.250 & 0.983 & 0.667 \\
0.850 & 357.4 & 412.5 & 0.197 & 0.991 & 0.645 \\
0.898 & 357.5 & 415.8 & & 0.996 & 0.625 \\
0.949 & 357.1 & 418.4 & 0.091 & 0.999 & 0.604 \\
1.000 & & 424.0 & 0.000 & 1 & 0.586
\end{tabular}

Table 4. Measured Solid-Liquid Equilibrium Data for the 3,4,5-Trimethoxybenzoic Acid (1) + 2,4,5-Trimethoxybenzoic Acid (2) Binary System

\begin{tabular}{cccccl}
\hline$x_{1}$ & $T_{\mathrm{E}} / \mathrm{K}$ & $T_{\mathrm{L}} / \mathrm{K}$ & $f_{\mathrm{E}}$ & $\gamma_{1}$ & \multicolumn{1}{c}{$\gamma_{2}$} \\
\hline 0.000 & & 417.9 & 0.000 & 1.189 & 1 \\
0.050 & 395.6 & 414.6 & 0.092 & 1.178 & 1 \\
0.100 & 396.2 & 412.1 & 0.228 & 1.168 & 1.001 \\
0.150 & 396.3 & 408.7 & 0.415 & 1.157 & 1.002 \\
0.200 & 395.8 & 406.0 & 0.662 & 1.146 & 1.004 \\
0.250 & 395.9 & 402.5 & & 1.135 & 1.007 \\
0.401 & 396.0 & 405.7 & & 1.101 & 1.022 \\
0.451 & 396.1 & 408.6 & 0.826 & 1.089 & 1.03 \\
0.500 & 396.2 & 412.7 & 0.743 & 1.078 & 1.04 \\
0.600 & 396.1 & 421.6 & 0.576 & 1.055 & 1.067 \\
0.650 & 396.0 & 424.2 & 0.493 & 1.045 & 1.084 \\
0.699 & 395.7 & 428.1 & 0.432 & 1.035 & 1.105 \\
0.800 & 395.9 & 433.3 & & 1.017 & 1.162 \\
0.850 & 395.4 & 435.5 & 0.191 & 1.01 & 1.199 \\
0.900 & 395.8 & 438.0 & 0.132 & 1.005 & 1.255 \\
0.950 & 395.4 & 441.4 & & 1.001 & 1.299 \\
1.000 & & 444.5 & 0.000 & 1 & 1.366
\end{tabular}

each binary mixture that are evaluated by minimizing the following objective function between calculated and experimentally determined liquidus temperatures:

$$
\operatorname{obj}=\sum_{k=1}^{N}\left(\frac{1}{N}\right)\left\{\frac{T_{\mathrm{L}}^{\text {calcd }}-T_{\mathrm{L}}^{\text {exptl }}}{T_{\mathrm{L}}^{\text {exptl }}}\right\}_{k}
$$

The subscript $k$ denotes the $k$ th data point. The calculated SLE phase boundaries from the Wilson model are then compared with the experimentally measured results.

\section{Results and Discussion}

The experimentally measured eutectic temperatures $\left(T_{\mathrm{E}}\right)$ and liquidus temperatures $\left(T_{\mathrm{L}}\right)$ for three binary systems of isomeric compounds at various compositions are presented in Tables 2 to 4, respectively. The uncertainties in the experimental temperatures and compositions are \pm 0.2 $\mathrm{K}$ and \pm 0.002 mole fraction, respectively. For each binary system, the fractional transformation data are calculated using eq 3, and a typical plot is shown in Figure 1 for 4 -(acetylamino)toluene $(1)+2$-(acetylamino)toluene (2) at $x_{1}=0.05$. All three binary systems in this study show simple eutectic behavior. A sharp transition point is observed in Figure 1 where the eutectic temperature and the fractional transformation value at the eutectic temperature $f_{\mathrm{E}}$ (eutectic fraction) are easily determined. Plots of the $f_{\mathrm{E}}$ values at various compositions for each binary 
Table 5. Optimally Fitted Binary Parameters of the Wilson Model and the Deviations of Regression

$$
\begin{array}{r}
\text { Wilson parameters } \\
\lambda_{12}-\lambda_{11} \\
R
\end{array} \frac{\lambda_{21}-\lambda_{22}}{R}
$$

\begin{tabular}{lcc}
\multicolumn{1}{c}{ binary systems } & $(\mathrm{K})$ & $\mathrm{AADT}(\%)^{b}$ \\
\hline $\begin{array}{l}\text { 3-aminophenol (1) } \\
+ \text { 2-aminophenol (2) }\end{array}$ & $274.4 / 137.9$ & 0.37 \\
$\begin{array}{l}\text { 4-(acetylamino)toluene (1) } \\
\text { + 2-(acetylamino)toluene (2) }\end{array}$ & $55.0 /-278.3$ & 0.41 \\
$\begin{array}{l}\text { 3,4,5-trimethoxybenzoic acid (1) } \\
+2,4,5 \text {-trimethoxybenzoic acid (2) }\end{array}$ & $-149.5 / 316.3$ & 0.24
\end{tabular}

${ }^{a}$ The Wilson equations are

$$
\begin{gathered}
\ln \gamma_{1}=-\ln \left(x_{1}+\Lambda_{12} x_{2}\right)+x_{2}\left[\frac{\Lambda_{12}}{x_{1}+\Lambda_{12} x_{2}}-\frac{\Lambda_{21}}{\Lambda_{21} x_{1}+x_{2}}\right] \\
\ln \gamma_{2}=-\ln \left(x_{2}+\Lambda_{21} x_{1}\right)+x_{1}\left[\frac{\Lambda_{21}}{x_{2}+\Lambda_{21} x_{1}}-\frac{\Lambda_{12}}{\Lambda_{12} x_{2}+x_{1}}\right] \\
\Lambda_{12}=\frac{V_{2}}{V_{1}} \exp \left(-\frac{\lambda_{12}-\lambda_{11}}{R T}\right) \\
\Lambda_{21}=\frac{V_{1}}{V_{2}} \exp \left(-\frac{\lambda_{21}-\lambda_{22}}{R T}\right)
\end{gathered}
$$

where $V_{1}$ and $V_{2}$ are the liquid molar volumes. For isomers, the ratios of liquid molar volumes are assumed to be unity.

${ }^{b} \operatorname{AADT}(\%)=\frac{100}{N} \sum_{k=1}^{N}\left|\frac{T_{\mathrm{L}}^{\text {calcd }}-T_{\mathrm{L}}^{\text {exptl }}}{T_{\mathrm{L}}^{\text {exptl }}}\right|_{k}$

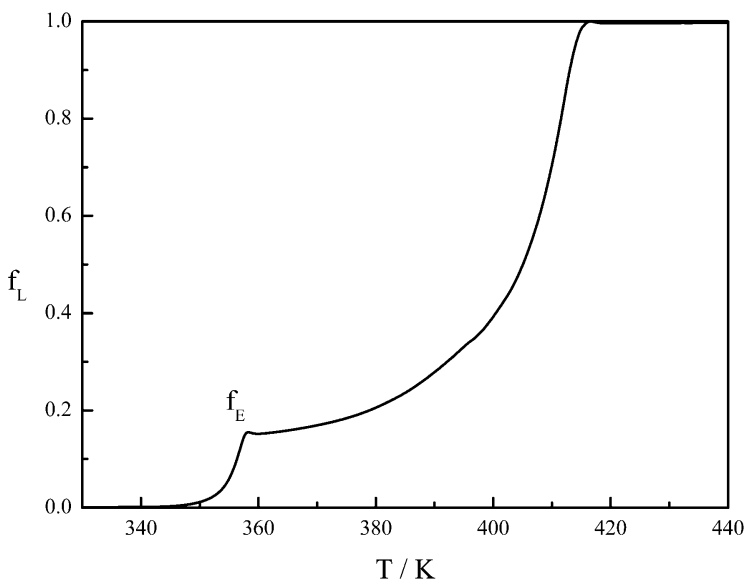

Figure 1. Fraction transformation $f_{\mathrm{L}}$ for the 4-(acetylamino)toluene (1) +2 -(acetylamino)toluene (2) binary system at $x_{1}=0.05$.

system are shown in Figures 2 to 4 . At the eutectic point of a binary mixture, the $f_{\mathrm{E}}$ value approaches unity. The eutectic composition for each binary system is thus easily determined from Figures 2 to 4 . As indicated in our previous study, ${ }^{3}$ one advantage of the eutectic fraction plot in determining the eutectic composition is to avoid the error due to small samples in the DSC experiments. The DSC experiments are difficult for mixtures near the eutectic composition, owing to the overlap of the DSC peaks. The fractional transformation method, however, provides a convenient way to locate the eutectic point without experimental data near the eutectic composition. The $f_{\mathrm{E}}$ data at various compositions for each binary mixture are also shown in Tables 2 to 4 , respectively.

Table 5 presents the optimally fitted binary parameters of the Wilson model as well as the calculated deviation in liquidus temperatures. It is observed that with the optimal binary parameters the Wilson model correlates the experi-

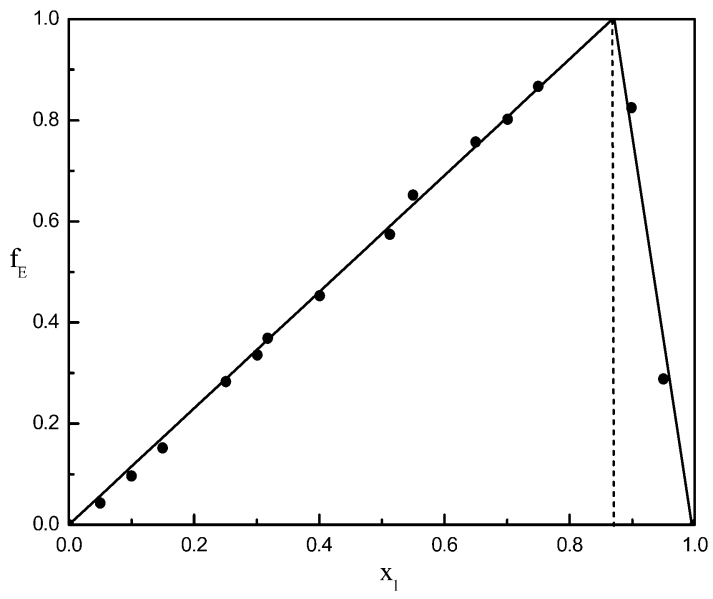

Figure 2. Eutectic fraction $f_{\mathrm{E}}$ for the binary mixture of 3-aminophenol (1) +2 -aminophenol (2); the eutectic composition is at $x_{1 \mathrm{E}}$ $=0.865$.

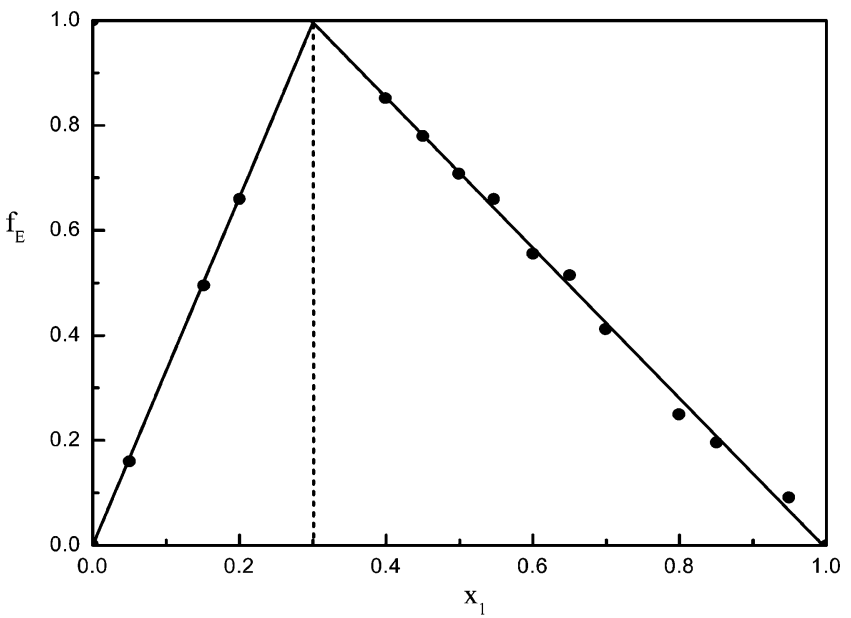

Figure 3. Eutectic fraction $f_{\mathrm{E}}$ for the binary mixture of 4-(acetylamino)toluene (1) + 2-(acetylamino)toluene (2); the eutectic composition is at $x_{1 \mathrm{E}}=0.300$

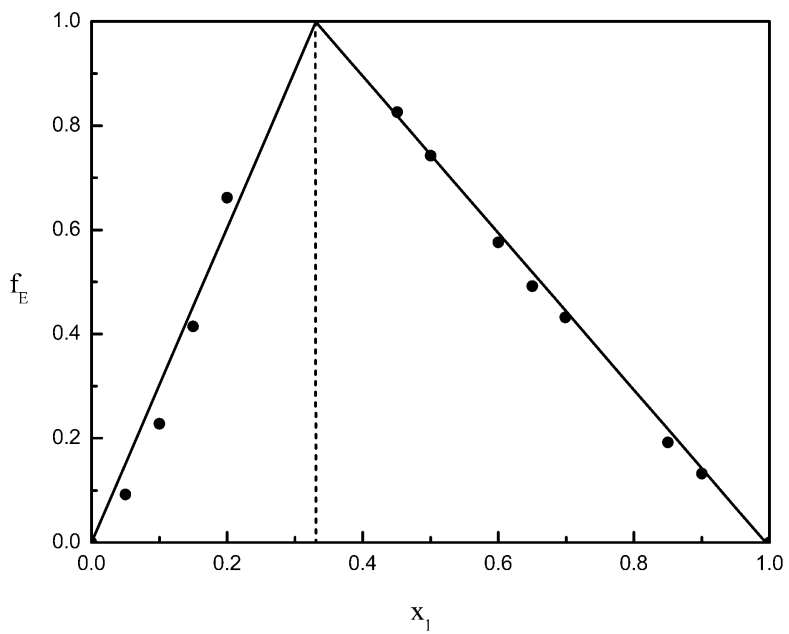

Figure 4. Eutectic fraction $f_{\mathrm{E}}$ for the binary mixture of the 3,4,5trimethoxybenzoic acid (1) $+2,4,5$-trimethoxybenzoic acid (2) system; the eutectic composition is at $x_{1 \mathrm{E}}=0.331$.

mental data satisfactorily. The absolute average percentage deviations for the calculation of liquidus temperatures are all less than $0.4 \%$. Graphical presentations for the calculated phase boundaries of a typical binary system of 4 -(acetylamino)toluene (1) +2 -(acetylamino)toluene (2) and 


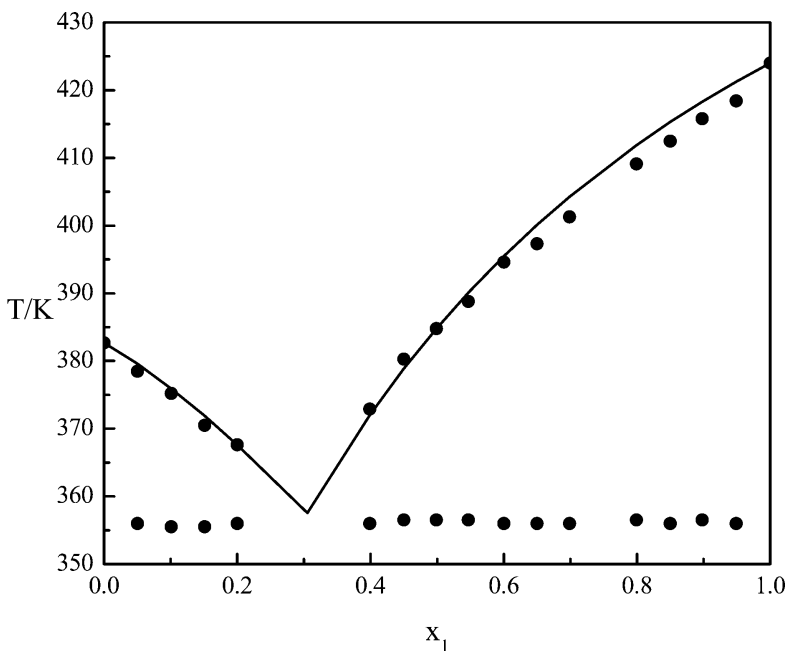

Figure 5. Measured data and calculated SLE results for the binary mixture of the 4-(acetylamino)toluene (1) + 2-(acetylamino)toluene (2) system. (• DSC; -, Wilson equation).

Table 6. Comparison of the Eutectic Point Results from Various Methods for Three Binary Mixtures

\begin{tabular}{|c|c|c|}
\hline method & $\begin{array}{c}\text { eutectic } \\
\text { composition, } x_{1 \mathrm{E}} \\
\end{array}$ & $T_{\mathrm{E}} / \mathrm{K}$ \\
\hline \multicolumn{3}{|c|}{$\begin{array}{l}\text { 3-Aminophenol (1) } \\
+ \text { 2-Aminophenol (2) }\end{array}$} \\
\hline Wilson equation & 0.777 & 384.6 \\
\hline DSC experiment & 0.855 & 376.5 \\
\hline fractional transformation method & 0.865 & \\
\hline \multicolumn{3}{|c|}{$\begin{array}{l}\text { 4-(Acetylamino)toulene }(1) \\
+2 \text {-(Acetylamino)toulene }(2)\end{array}$} \\
\hline Wilson equation & 0.305 & 357.6 \\
\hline DSC experiment & 0.301 & 357.2 \\
\hline fractional transformation method & 0.300 & \\
\hline \multicolumn{3}{|c|}{$\begin{array}{l}\text { 3,4,5-Trimethoxybenzoic Acid ( } 1 \text { ) } \\
+2,4,5 \text {-Trimethoxybenzoic Acid ( } 2)\end{array}$} \\
\hline Wilson equation & 0.357 & 399.0 \\
\hline DSC experiment & 0.326 & 395.8 \\
\hline fractional transformation method & 0.331 & \\
\hline
\end{tabular}

the comparisons with experimental data are shown in Figure 5.
The eutectic-point compositions and temperatures for three binary systems in this study are shown in Table 6 on the basis of the experimental observations and various calculations. The eutectic composition and temperature for 3 -aminophenol (1) +2 -aminophenol (2) are $x_{1 \mathrm{E}}=0.86$ and $T_{\mathrm{E}}=376.5 \mathrm{~K}$. Those for 4 -(acetylamino)toluene (1) + 2 -(acetylamino)toluene (2) are $x_{1 \mathrm{E}}=0.30$ and $T_{\mathrm{E}}=357.2$ $\mathrm{K}$, and those for 3,4,5-trimethoxybenzoic acid (1) $+2,4,5$ trimethoxybenzoic acid (2) are $x_{1 \mathrm{E}}=0.33$ and $T_{\mathrm{E}}=395.8$ $\mathrm{K}$. The calculated eutectic compositions for all three binary systems using the fractional transformation method are in good agreement with the experimentally measured DSC data. It is again shown as a simple and reliable method to determine the eutectic points for binary mixtures.

\section{Literature Cited}

(1) Wittig, R.; Constantinescu, D.; Gmehling, J. Binary Solid-Liquid Equilibria of Organic Systems Containing $\epsilon$-Caprolactone. $J$. Chem. Eng. Data 2001, 46, 1490-1493.

(2) Flotter, E.; Hollander, B.; de Loos, T. W.; de Swaan Arons, J. Ternary System ( $n$-Heptane + Docosane + Tetracosane): The Solubility of Mixtures of Docosane in Heptane and Data on SolidLiquid and Solid-Solid Equilibria in the Binary System (Docosane + Tetracosane). J. Chem. Eng. Data 1997, 42, 562-565.

(3) Huang, C. C.; Chen, Y. P. Measurements and model prediction of the solid-liquid equilibria of organic binary mixtures. Chem. Eng. Sci. 2000, 55, 3175-3185.

(4) Hammani, A.; Mehrotra, A. K. Nonisothermal crystallization kinetics of n-paraffins withn chain lengths between thirty and fifty. Thermochimica 1992, 211, 137-153.

(5) Matsuoka, M.; Ozawa, R. Determination of solid-liquid-phase equilibria of binary organic systems by differential scanning calorimetry. J. Cryst. Growth 1989, 96, 596-604.

(6) Gray, A. P. Analytical Chemistry; Plenum Press: New York, 1968; pp 209-218.

(7) Prausnitz, J. M.; Lichtenthaler, R. N.; de Azeredo, E. G. Molecular Thermodynamics of Fluid Phase Equilibria, 3rd ed.; Prentice Hall: New York, 1999.

(8) Wilson, G. M. Vapor-Liquid Equilibrium. XI: A New Expression for the Excess Energy of Mixing. J. Am. Chem. Soc. 1964, 86, 127-130.

(9) CRC Handbook of Chemistry and Physics, 83rd ed.; Lide, D. R., Ed.; CRC Press: Boca Raton, FL, 2002.

Received for review March 30, 2004. Accepted October 3, 2004.

JE049878M 